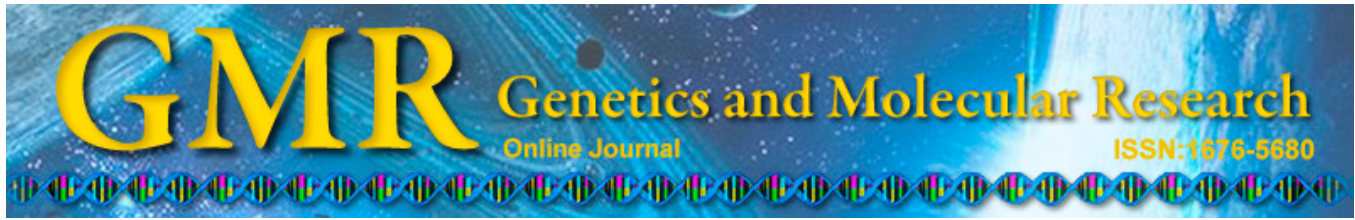

\title{
Radiofrequency thermocoagulation combined with pulsed radiofrequency helps relieve postoperative complications of trigeminal neuralgia
}

\author{
W.-X. Zhao, Q. Wang, M.-W. He, L.-Q. Yang, B.-S. Wu and J.-X. Ni \\ Department of Pain Management, Xuanwu Medical University, \\ Xuanwu, Beijing, China \\ Corresponding author: J.-X. Ni \\ E-mail: nijiaxiang@263.net
}

Genet. Mol. Res. 13 (3): 7616-7623 (2015)

Received July 22, 2014

Accepted October 21, 2014

Published July 13, 2015

DOI http://dx.doi.org/10.4238/2015.July.13.5

\begin{abstract}
Trigeminal neuralgia is a sudden, severe condition characterized by stabbing and recurrent pain. Radiofrequency thermocoagulation (RFT) and pulsed radiofrequency (PRF) are common surgical interventions used to treat trigeminal neuralgia. This study aimed to investigate the therapeutic effects and associated complications of a combination of RFT and PRF in the treatment of trigeminal neuralgia. Computed tomography-guided percutaneous RFT of the Gasserian ganglion was performed on 80 patients with trigeminal neuralgia. Patients were randomly assigned to either group A (RFT at $70^{\circ} \mathrm{C}$ ) or group B (RFT at $\left.75^{\circ} \mathrm{C}\right)$. Patients in each group were divided into 2 subgroups, receiving percutaneous RFT (240 s) with or without PRF $\left(42^{\circ} \mathrm{C}, 2 \mathrm{~Hz}, 240 \mathrm{~s}\right)$. Six months later, pain relief and complication status were evaluated. There was no significant difference in visual analogue scores among groups with RFT at $70^{\circ}$ or $75^{\circ} \mathrm{C}$, with or without PRF. Data showed that facial numbness and postoperative masticatory muscle weakness recovered more rapidly in patients receiving combined
\end{abstract}


RFT and PRF treatment. Decreased corneal reflex was relieved to a significantly greater extent in groups receiving PRF than those without. Thus, compared to the use of RFT at $75^{\circ} \mathrm{C}$ alone, the combination of PRF and RFT helped eliminate postoperative complications, such as facial numbness, masticatory muscle weakness, and decreased corneal reflex, indicating that it could be useful for surgically treating trigeminal neuralgia.

Key words: Trigeminal neuralgia; Gasserian ganglion; Complications; Radiofrequency thermocoagulation; Pulsed radiofrequency

\section{INTRODUCTION}

Trigeminal neuralgia (TN) is a pain syndrome characterized by recurrent attacks and severe pain typically in the area innervated by the trigeminal nerve. It is a common disorder having great impact on the quality of life of patients (Yoshino et al., 2003; Han et al., 2010). Besides medication and interventional procedures, radiofrequency thermocoagulation (RFT) is one of the most important surgical approaches extensively applied in the treatment of TN.

The main advantage of conventional RFT is its effectiveness and high rate of pain relief. However, patients receiving RFT may develop complications, such as facial numbness, decreased corneal reflex, masticatory muscle weakness (van Kleef et al., 2009), and intracranial hemorrhage (Rath et al., 2009). These complications are presumably due to neuronal injury mainly produced by surgical puncture and heat from radiofrequency temperature during the surgery (Bogduk et al., 1987). Research has focused on ways to decrease complications while maintaining long-term therapeutic effects. In 1998, Sluijter et al. (1998) first proposed the concept of pulsed radiofrequency (PRF), in which high-density voltage $\left(2 \times 10^{4} \mathrm{~A} / \mathrm{m}^{2}\right)$ is produced at the tip of a needle by a radiofrequency generator and the current is conducted to the nerve in a pulsed fashion. The temperature at the tip of the electrode does not exceed $42^{\circ} \mathrm{C}$ and does not damage the nerve. Although PRF is reported to be ineffective for pain treatment in idiopathic TN (Erdine et al., 2007; Luo et al., 2014), it was suggested that computed tomography (CT)-guided PRF was associated with less complications than RFT (Luo et al., 2014), believed to be caused by the neural regulation induced by RFT. Thus, we speculate that the combined use of conventional RFT and PRF may retain the advantages of pain relief while reducing complications after treatment.

In this study, we investigated postoperative therapeutic effects and complications of CTguided RFT at different temperatures with or without PRF in the treatment of TN.

\section{MATERIAL AND METHODS}

\section{Methods}

\section{Patients}

A total of 80 patients with trigeminal neuralgia, 34 men and 46 women, aged 38-81 years (mean age, 59.3 years), were included in this study. The time of disease onset ranged between 0.5-30 years, with a mean age of 5.9 years. Patients had to fulfill certain inclusion criteria 
to be included in the study. Thus, the following patients were included: those with moderate or heavy primary trigeminal neuralgia diagnosed during physical examination; aged and infirm patients with trigeminal neuralgia who were not suitable/willing to receive microvascular decompression; patients on a high dose of carbamazepine or phenytoin sodium. Patients were excluded from the study if they fulfilled one of the following criteria: noncompliance with physician's advice, infection foci on the skin and deep tissue at the puncture site, or the presence of bleeding tendency or receiving anticoagulant therapy. In addition, patients in the unstable stage of severe cardiovascular or cerebrovascular disease or with secondary trigeminal neuralgia (for example, trigeminal neuralgia secondary to cranial tumors or herpes zoster, etc.) were also excluded. All patients showed no statistically significant difference in visual analogue scores (VAS), facial numbness, masticatory muscle weakness, or decrease in corneal reflex.

\section{Grouping method}

In a controlled study, 80 patients were randomly and equally assigned to four treatment groups (20 patients in each): groups $\mathrm{A} 1$ and $\mathrm{A} 2$ were treated with $\mathrm{RFT}$ at $70^{\circ} \mathrm{C}$, whereas groups $\mathrm{B} 1$ and $\mathrm{B} 2$ were treated with RFT at $75^{\circ} \mathrm{C}$. Before the RFT operation, patients in both group A1 and B1 received PRF. Grouping details are listed in Table 1 below.

Table 1. Patient groups.
\begin{tabular}{lccc}
\hline \multicolumn{3}{c}{ Group A } & \multicolumn{3}{c}{ Group B } \\
\cline { 3 - 4 } A1 (PRF + RFT) & A2 (Sham Test + RFT) & B1 (PRF + RFT) & B2 (Sham Test + RFT) \\
\hline 20 & 20 & 20 & 20 \\
\hline
\end{tabular}

\section{Surgical procedure}

The patient was placed in a supine position on the CT bed, so that the connecting line between the mental protuberance and the angle of the mandible was perpendicular to the bed. Electrocardiography, blood pressure, and blood oxygen saturation were continuously monitored. Using the puncture method in an anterior approach, a metal marker was placed at a site on the lateral side of the labial angle, a site near the cheekbone above the second molars of the upper jaw. A CT location measurement of the distance between the punctured skin and the oval foramen and of the puncture angle was carried out to determine the punctured site and the puncture path (as shown in Figure 1A and B).

Full disinfection was carried out with Anerdian and a sterile drape was spread. Local anesthesia was induced with $1 \%$ lidocaine and the puncture was made by the radiofrequency trocar in the CT-determined direction. During puncturing, penetration of the oral mucous membrane was avoided, as this could increase the chance of intracranial infection. When the puncture needle entered the oval foramen there was a sense of penetration and the patient experienced a severe shock-like pain, suggesting the puncture needle had penetrated the Gasserian ganglion. Another CT scan was carried out to determine the position of the puncture needle and the impedance in the area around the puncture needle tip was displayed; when the puncture needle tip was located in the ganglion, the impedance was approximately 300-500 $\Omega$, further confirming that the needle tip was correctly located in the Gasserian ganglion. 

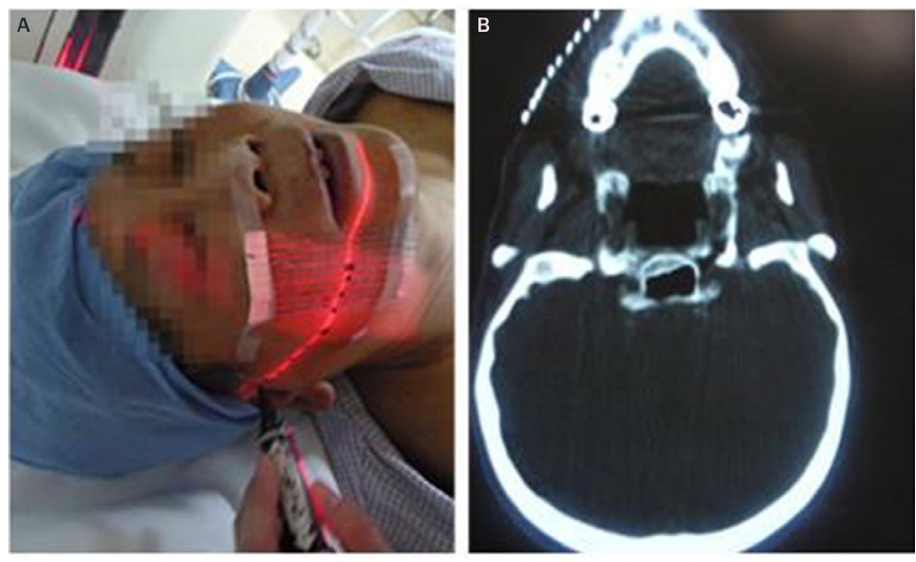

Figure 1. Puncture site and the puncture path. A. CT-positioning surface for puncture point. B. CT scan showing puncture path.

After the successful puncture, RFT or PRF was administered with a radiofrequency generator (German Baylis Radiofrequency Therapy Apparatus, PMG-230-TD). The patients in group A received RFT at $70^{\circ} \mathrm{C}$ for $120 \mathrm{~s}$. In case there were two or more nerve branches, the puncture needle was withdrawn by $0.3 \mathrm{~cm}$ and RFT was then applied at $70^{\circ} \mathrm{C}$ for another 120 s. Prior to RFT, patients in group A1 received a PRF current of 2 bursts at $20 \mathrm{~ms} / \mathrm{s}$ for $120 \mathrm{~s}$. The tip of the electrode did not exceed $42^{\circ} \mathrm{C}$. To avoid any bias, patients in group A2 received a $120 \mathrm{~s}$ puncture needle piercing without any operation. Surgical procedures performed on patients in group B were the same as those in group A.

\section{Observations and follow-up}

VAS: VASs of patients before surgery were recorded, as well as 1 day, 1 week, 2 weeks, 1 month, 3 months, and 6 months after the surgery. Score range: "0" no pain to " 10 " worst possible pain.

Facial numbness before and after the operation: "0" no numbness; " 1 " mild numbness (tolerable, without significant impact on life or work); "2" moderate numbness (with some impact on life); "3" severe numbness (intolerable).

Corneal reflex prior to and after the procedure: "0" normal corneal reflex; "1" decreased corneal reflex.

Masticatory muscle weakness prior to and after the procedure: " 0 " no impact, " 1 " tolerable masticatory muscle weakness, without significant impact on life or work; "2" moderate masticatory muscle weakness, with significant impact on life; "3" severe masticatory muscle weakness.

Data from one patient in group B1 is missing, as the patient did not return for follow-up visits.

\section{Statistics}

Statistics were performed using the SAS and SPSS 14.0 software. The effects of grouping and time, as well as postoperative VAS and numbness, were analyzed by the gener- 
alized estimated equation. Postoperative masticatory muscle weakness was analyzed by the rank sum test, and postoperative corneal reflex, by the chi-square test.

\section{RESULTS}

Generally, there were no statistically significant differences of VAS among groups and the different time-points after the procedure. Facial numbness in all patients decreased 6 months after the procedure. Compared with group A2, patients in group A1 had lower level of facial numbness 6 months after surgery (Table 2$)(P<0.05)$. The postoperative masticatory muscle weakness was less severe in patients of group A than in group B (Table 3). The complication of postoperative masticatory muscle weakness recovered more rapidly in group A1 patients than in group A2 (Table 4). Furthermore, the decreased corneal reflex of group A1 and B1 patients that received both PRF and RFT was significantly relieved compared with group A2 and B2 who just had RFT (Table 5).

Table 2. Effect of time on facial numbness (means \pm SD).
\begin{tabular}{lcccr}
\hline Time after surgery & A1 & A2 & B1 & B2 \\
\hline 1 day & $1.05 \pm 0.60$ & $1.20 \pm 0.68$ & $1.37 \pm 0.83$ & $1.37 \pm 0.83$ \\
1 week & $1.05 \pm 0.60$ & $1.20 \pm 0.68$ & $1.37 \pm 0.83$ & $1.45 \pm 0.60$ \\
2 weeks & $1.05 \pm 0.60$ & $1.20 \pm 0.67$ & $1.31 \pm 0.82$ & $1.40 \pm 0.59$ \\
1 month & $1.05 \pm 0.51$ & $1.20 \pm 0.73$ & $1.21 \pm 0.79$ & $1.35 \pm 0.58$ \\
3 months & $1.00 \pm 0.61$ & $1.15 \pm 0.76$ & $1.21 \pm 0.79$ & $1.20 \pm 0.69$ \\
6 months & $0.75 \pm 0.51^{*}$ & $0.95 \pm 0.70$ & & \\
\hline
\end{tabular}

$* \mathrm{P}<0.05$, compared with Group A2.

Table 3. Effects of group on postoperative masticatory muscle weakness (means \pm SD).

\begin{tabular}{lcc}
\hline Time after surgery & A & B \\
\hline 1 day & $0.58 \pm 0.59$ & $0.82 \pm 0.76$ \\
1 week & $0.58 \pm 0.59$ & $0.84 \pm 0.75$ \\
weeks & $0.58 \pm 0.59$ & $0.82 \pm 0.76$ \\
1 month & $0.56 \pm 0.59$ & $0.82 \pm 0.76$ \\
months & $0.53 \pm 0.60$ & $0.82 \pm 0.76$ \\
6 months & $0.48 \pm 0.60^{*}$ & $0.79 \pm 0.73$ \\
\hline
\end{tabular}

$* \mathrm{P}<0.05$, compared with Group B after 6 months.

\begin{tabular}{|c|c|c|c|c|}
\hline Time after surgery & A1 & $\mathrm{A} 2$ & $\mathrm{~B} 1$ & B2 \\
\hline 1 day & $0.44 \pm 0.51$ & $0.70 \pm 0.66$ & $0.63 \pm 0.83$ & $1.00 \pm 0.65$ \\
\hline 1 week & $0.47 \pm 0.51$ & $0.70 \pm 0.66$ & $0.67 \pm 0.84$ & $1.00 \pm 0.65$ \\
\hline 2 weeks & $0.47 \pm 0.51$ & $0.70 \pm 0.66$ & $0.63 \pm 0.83$ & $1.00 \pm 0.65$ \\
\hline 1 month & $0.42 \pm 0.50$ & $0.70 \pm 0.66$ & $0.63 \pm 0.83$ & $1.00 \pm 0.65$ \\
\hline 3 months & $0.42 \pm 0.51$ & $0.65 \pm 0.67$ & $0.63 \pm 0.83$ & $1.00 \pm 0.65$ \\
\hline 6 months & $0.36 \pm 0.50 *$ & $0.50 \pm 0.68$ & $0.63 \pm 083$ & $0.95 \pm 0.60$ \\
\hline
\end{tabular}

$* \mathrm{P}<0.05$. 


Table 5. Number of patients with postoperative decreased corneal reflex.
\begin{tabular}{lccccr}
\hline Grade & \multicolumn{2}{c}{ Group A } & & Group B \\
\cline { 2 - 6 } & A1 & A2 & B1 & 14 & B2 \\
\hline 0 (no effects) & 13 & 12 & $5 *$ & 11 \\
1 (decreased) & $7 *$ & & 9 \\
\hline
\end{tabular}

$* \mathrm{P}<0.05$, Group A1 compared with Group A2, Group B1 with Group B2.

\section{DISCUSSION}

RFT has been extensively used as an effective method for TN (Motamedi et al., 2009). An increased RFT temperature may increase effectiveness but may exacerbate postoperative complications, such as facial numbness, decreased corneal reflex, and masticatory muscle weakness (Bogduk et al., 1987). Previous studies suggested that thermocoagulation damages class $\mathrm{A}-\delta$ and $\mathrm{C}$ fibers that conduct pain signals, as well as nonmyelinated fibers that conduct epicritic stimuli. However, other experiments and histological results refuted these findings and supported the theory that all nerve fibers (including nonmyelinated and myelinated fibers) might be damaged even at low temperatures. Therefore, it seemed impossible to achieve both, complete pain relief and maintenance of epicritic sense.

In 1998, Sluijter et al. (1998) first proposed PRF. Although its long-term therapeutic effects were uncertain, short-term use of the method was suggested to be more favorable as it was accompanied by fewer complications. Several studies that investigated the mechanisms behind PRF (Higuchi et al., 2002a; Erdine et al., 2005; Podhajsky et al., 2005; Van Zundert et al., 2005) found the favorable effect of PRF was mainly due to following reasons. First, there was a change occurring in the structure of the cells that influenced the conduction of pain (Higuchi et al., 2002b). Second, there was an increased expression and delayed time of nonspecific c-fox genes, that also influenced the conduction of pain (Van Zundert et al., 2005). Third, the long-term inhibition of class $\mathrm{C}$ fibers may inhibit the conduction of pain signals (Sandkühler et al., 1997). However, the long-term therapeutic effects of the PRF technique in treatment of TN need further evaluation. It is unclear whether the combined use of conventional RFT and PRF may retain the advantage of pain relief while decreasing complications after treatment.

In this trial, a precise puncture of the Gasserian ganglion was guided by $\mathrm{CT}$. A radiofrequency apparatus was adapted to ensure the accuracy of PRF and RFT, which maximized the success rate of the puncture and minimized complications (Xu et al., 2005). The immediate pain relief rates in group A and B were 94.3 and 97.6\%, respectively, lower than those reported in the literature (Fraioli et al., 2009). Previous studies have reported immediate pain relief rates from RFT in the treatment of TN between 91-99\% (Bovaira et al., 2013; Kim et al., 2013; Weng et al., 2013).

Kanpolat et al. (2001) reported that $98.6 \%$ of 1600 patients felt immediate pain relief; however, the reasons for such differences are due to contrasting pain relief criteria. In the current study, the criteria for postoperative pain relief was $>50 \%$, while Kanpolat's criteria was postoperative pain relief $>40 \%$. There was no statistically significant difference of VAS between groups A and B, suggesting that $70^{\circ}$ and $75^{\circ} \mathrm{C}$ RFT had similar postoperative shortterm pain relief rates in the treatment of TN (the follow-up in this article was 6 months after the procedure). 
In the current study, postoperative masticatory muscle weakness in group A was significantly decreased compared with that in group B. The incidences of postoperative masticatory muscle weakness were 45 and $64 \%$ in groups A and B, respectively. There was a statistically significant difference of postoperative masticatory muscle weakness between the subgroups within groups A and $\mathrm{B}(\mathrm{P}=0.027)$. However, VAS of group A $\left(\mathrm{RFT}\right.$ at $\left.70^{\circ} \mathrm{C}\right)$ was similar to that of group $\mathrm{B}\left(\mathrm{RFT}\right.$ at $\left.75^{\circ} \mathrm{C}\right)$. This suggests that RFT at $70^{\circ} \mathrm{C}$ significantly decreases motor nerve damage without affecting therapeutic effects. Additionally, the complication of postoperative masticatory muscle weakness recovered more rapidly in group A1 than in group A2. This is probably due to the combined use of RFT and PRF. However, the mechanism underlying this result needs further elucidation.

The incidence of postoperative corneal reflex in groups A1 and B1 with PRF was lower than that in groups $\mathrm{A} 2$ and $\mathrm{B} 2$ without PRF. The nasociliary nerve responsible for the corneal reflex is a branch of the ophthalmic nerve, which itself is a branch of the trigemical nerve. The nerve that conducts pain is thought to be less damaged in patients with RFT at $70^{\circ} \mathrm{C}$.

In this study, the incidence of postoperative facial numbness in groups A and B was 85 and $86 \%$, respectively, different from those in the study previously performed by Fraioli et al. (2009). This difference was probably due to the disparate RFT temperatures used between the two studies. Fraioli et al. (2009) administered radiofrequencies at a temperature of $90^{\circ}-95^{\circ} \mathrm{C}$ for $10 \mathrm{~min}$. The incidence of postoperative facial numbness in this study was $100 \%$. There was no statistically significant difference in the incidence of facial numbness between groups A and B. However, when the time factor was considered, postoperative facial numbness improved and corneal reflex recovered more rapidly in group A, while there was no statistically significant difference between the two indices in group B. This suggests that when using $70^{\circ} \mathrm{C}$ RFT, complications such as facial numbness and corneal reflex can be relieved over time.

Nguyen and Wilkes (2010) carried out PRF in patients with sphenopalatine neuralgia and reported that after the therapy, patient pain disappeared. Despite recurrent attacks, the final therapeutic effects were positive. In the current trial, it was found through a comparison among time points that postoperative corneal reflexes were better in group B1 with PRF than in group B2 without PRF. However, there was no statistically significant difference in corneal reflex between groups A1 and A2. It is speculated that PRF may have strong regulatory effects on severely damaged nerves; however, the mechanism behind it needs further investigation.

In conclusion, RFT at $70^{\circ} \mathrm{C}$ could provide acceptable overall pain relief in the treatment of trigeminal neuralgia than RFT at $75^{\circ} \mathrm{C}$. Additionally, compared with the use of RFT only, the combined use of PRF and RFT could help eliminate complications such as facial numbness, masticatory muscle weakness, and decreased corneal reflex.

\section{REFERENCES}

Bogduk N, Macintosh J and Marsland A (1987). Technical limitations to the efficacy of radiofrequency neurotomy for spinal pain. Neurosurgery 20: 529-535.

Bovaira M, Penarrocha M, Penarrocha M and Calvo A (2013). Conventional radiofrequency treatment in five patients with trigeminal neuralgia. Med. Oral. Patol. Oral. Cir. Bucal 18: 76-80.

Erdine S, Yucel A, Cimen A, Aydin S, et al. (2005). Effects of pulsed versus conventional radiofrequency current on rabbit dorsal root ganglion morphology. Eur. J. Pain 9: 251-256.

Erdine S, Ozyalcin NS, Cimen A, Celik M, et al. (2007). Comparison of pulsed radiofrequency with conventional radiofrequency in the treatment of iopathic trigeminal neuralgia. Eur. J. Pain 11: 309-313.

Fraioli MF, Cristino B, Moschettoni L, Cacciotti G, et al. (2009). Validity of percutaneous controlled radiofrequency thermocoagulation in the treatment of isolated third division trigeminal neuralgia. Surg. Neurol. 71: 180-183. 
Han I, Shin D, Chang J, Kim K, et al. (2010). Effect of various surgical modalities in recurrent or persistent trigeminal neuralgia. Stereot. Funct. Neuros. 88: 156-162.

Higuchi Y, Nashold BS, Sluijter M, Cosman E, et al. (2002a). Exposure of the dorsal root ganglion in rats to pulsed radiofrequency currents activates dorsal horn lamina I and II neurons. Neurosurgery 50: 850-855.

Higuchi Y, Nashold B, Sluijter M and Cosman E (2002b). Pealstein radiofrequency currents activates dorsal horn lamina I and II neurons. Neurosurgery 50: 850-856.

Kanpolat Y, Savas A, Bekar A and Berk C (2001). Percutaneous controlled radiofrequency trigeminal rhizotomy for the treatment of idiopathic trigeminal neuralgia: 25-year experience with 1,600 patients. Neurosurgery 48: 524-532.

Kim JH, Yu HY, Park SY, Lee SC, et al. (2013). Pulsed and conventional radiofrequency treatment: which is effective for dental procedure-related symptomatic trigeminal neuralgia? Pain Med. 14: 430-435.

Luo F, Shen Y, Wang T, Meng L, et al. (2014). 3D CT-Guided pulsed radiofrequency treatment for trigeminal neuralgia. Pain Pract. 14: 16-21.

Motamedi MH, Rahmat H, Bahrami E, Sadidi A, et al. (2009). Trigeminal neuralgia and radiofrequency. J. Calif. Dent. Assoc. 37: 109-114.

Nguyen M and Wilkes D (2010). Pulsed radiofrequency V2 treatment and intranasal sphenopalatine ganglion block: a combination therapy for atypical trigeminal neuralgia. Pain Pract. 10: 370-374.

Podhajsky RJ, Sekiguchi Y, Kikuchi S and Myers RR (2005). The histologic effects of pulsed and continuous radiofrequency lesions at 42 degrees $C$ to rat dorsal root ganglion and sciatic nerve. Spine 30: 1008-1013.

Rath GP, Dash HH, Bithal PK and Goyal V (2009). Intracranial hemorrhage after percutaneous radiofrequency trigeminal rhizotomy. Pain Pract. 9: 82-84.

Sluijter ME, Cosman ER, Rittmann WB and Van Kleef M (1998). The effects of pulsed radiofrequency fields applied to the dorsal root ganglion - a preliminary report. Pain Clin. 11: 109-117.

Sandkühler J, Chen JG, Cheng G and Randić M (1997). Low-frequency stimulation of afferent A delta fibers induces longterm depression at primary afferent synapses with substantia gelatinosa neurons in the rat. J. Neurosci. 17: 6483-6491.

van Kleef M, van Genderen WE, Narouze S, Nurmikko TJ, et al. (2009). Trigeminal neuralgia. Pain Pract. 9: 252-259.

Van Zundert J, de Louw AJ, Joosten EA, Kessels AG, et al. (2005). Pulsed and continuous radiofrequency current adjacent to the cervical dorsal root ganglion of the rat induces late cellular activity in the dorsal horn. Anesthesiology 102: $125-131$.

Weng Z, Zhou X, Liu X, Wei J, et al. (2013). Perioperative pain in patients with trigeminal neuralgia undergoing radiofrequency thermocoagulation of the Gasserian ganglion. J. Craniofac. Surg. 24: 1298-12302.

$\mathrm{Xu} \mathrm{S}$, Chen T and Wu C (2005). Clinical study on CT-guided gasserian ganglion RFT in treatment of trigeminal neuralgia. Chin. J. Neurosurg. 443.

Yoshino N, Akimoto H, Yamada I, Nagaoka T, et al. (2003). Trigeminal neuralgia: Evaluation of neuralgic manifestation and site of neurovascular compression with 3D CISS MR imaging and MR angiography. Radiology 228: 539-545. 